\title{
FERNANDO PESSOA, CESÁRIO VERDE. SUAS CIDADES
}

\author{
Geraldo Augusto Fernandes'
}

Recebido: 28/09/2015

Aprovado: 10/02/2016

RESUMO: Não é desconhecido o culto da cidade, se isso paixão não for, da vida urbana prémoderna - em Cesário Verde - e a já modernista - em Fernando Pessoa. "Num bairro moderno", Cesário Verde, ao pintar os "transparentes" que matizam não só as casas, a natureza à sua volta, mas também as pessoas, tem um súbito insight: "que visão de artista! / Se eu transformasse os simples vegetais (...)/ Num ser humano que se mova e exista...". Pessoa-Caeiro, em "O guardador de rebanhos", parece oprimir-se "Na cidade [em que] as grandes casas fecham a vista à chave, / Escondem o horizonte, empurram o nosso olhar para longe de todo o céu, / Tornam-nos pequenos porque nos tiram o que os nossos olhos nos podem dar, / E tornam-nos pobres porque a nossa única riqueza é ver." O clima que deixa Verde em seu poema é, sob seu olhar, o de descobertas que alteram o eu lírico. Seria para Alberto Caeiro a cidade também lugar de descobertas ou seria onde nossos olhos são empurrados "para longe de todo o céu"? Pretendo, com esses dois poemas, estudar o olhar de Cesário e de Pessoa-Caeiro sobre a cidade.

Palavras-chave: Cidades, Impressionismo, Modernismo, Fernando Pessoa, Cesário Verde

\section{FERNANDO PESSOA, CESÁRIO VERDE. THEIR CITIES}

\begin{abstract}
It is not unknown the cult of the city in Cesário Verde and in the modernist Fernando Pessoa. "Num bairro moderno", Cesário Verde, by painting the "transparency" that tints not only the houses, the nature around him, but also the people, has a sudden insight, "que visão de artista! / Se eu transformasse os simples vegetais (...)/ Num ser humano que se mova e exista...". Pessoa-Caeiro in "O guardador de rebanhos" seems to become depressed in the city: "Na cidade [em que] as grandes casas fecham a vista à chave, / Escondem o horizonte, empurram o nosso olhar para longe de todo o céu, / Tornam-nos pequenos porque nos tiram o que os nossos olhos nos podem dar, / E tornam-nos pobres porque a nossa única riqueza é ver." The atmosphere that Verde shows in his poem is, under his eyes, of discoveries that change the lyrical self. Would the city be also a place of discoveries for Alberto Caeiro or would it be a place where our eyes are pushed away "para longe de todo o céu"? I intend, with these two poems, to study the look of Cesário and Pessoa-Caeiro over the city.
\end{abstract}

Keywords: Cities, Impressionism, Modernism, Fernando Pessoa, Cesário Verde

\footnotetext{
1 Professor Doutor em Literatura Portuguesa da Universidade Federal do Ceará.
} 
E eu passo tão calado como a Morte, Nesta velha cidade tão sombria, Chorando aflitamente a minha sorte E prelibando o cálice da agonia. Cesário Verde

Cada rua é um canal de uma Veneza de tédios

E que misterioso o fundo unânime das ruas, Das ruas ao cair da noite, ó Cesário Verde, ó Mestre, Ó do "Sentimento de um Ocidental!" Fernando Pessoa/Álvaro de Campos

Em sua $A$ memória vegetal, Umberto Eco escreve que "a memória tem duas funções. Uma, e é nela que todos pensam, é a de reter na lembrança os dados de nossa experiência precedente; mas a outra é também a de filtrá-los, de descartar alguns e conservar outros” (ECO, 2010, pp. 10-11). Mais à frente, ainda diz que nossa "memória seletiva, tão importante para nos permitir sobreviver como indivíduos, funciona também em nível social e permite a sobrevivência das comunidades" (idem, p. 15).

Gostaria de comentar essa referência à memória: primeiramente, a relação entre ela e os dois poetas sobre os quais pretendo escrever. Ao registrar suas impressões, Cesário Verde, como um fotógrafo, vai, enquanto perambula pela cidade, registrando não apenas as ações e os quadros que lhe oferece o cenário, mas também os colocando "num suporte especialmente destinado à escrita", como diz Jacques Le Goff². É correto que quem observa este cenário é um eu lírico que, em "Num bairro moderno", camufla o autor do poema. Cesário Verde, ao pintar os "transparentes" que matizam não só as casas, a natureza à sua volta, mas também as pessoas, tem um súbito insight: “que visão de artista! / Se eu transformasse os simples vegetais (...)/ Num ser humano que se mova e exista. / Cheio de belas proporções carnais?!” Ao fazê-lo, aplica, sob o olhar observador do eu lírico, aquilo que refere Eco: ele retém na lembrança os dados da experiência precedente, apesar de que, pela escrita do poema, a experiência está sendo registrada no momento por que perambula pelo bairro moderno. Como relata Massaud Moisés, “o eu lírico de Cesário

\footnotetext{
${ }^{2} \mathrm{O}$ estudioso comenta que a passagem da memorização oral para a escrita segue a repetição palavra por palavra, mas também permite um duplo progresso quanto ao desenvolvimento da memória. Um é a comemoração, forma de celebração de um acontecimento memorável, através da inscrição (em estelas e obeliscos, por exemplo, como também nos templos, cemitérios, praças etc.), outro é o documento escrito - que não deixa de ser inscrição - "num suporte especialmente destinado à escrita". (LE GOFF, 1996, p. 433).
} 


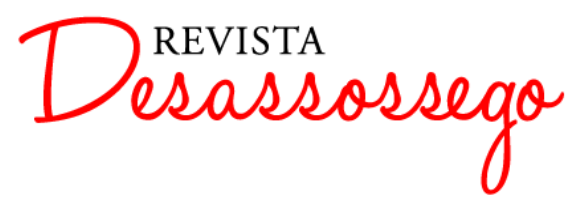

DESASSOSSEGO 15 | JUN/2016 | ISSN 2175-3180

DOI: http://dx.doi.org/10.11606/issn.2175-3180.v8i15p102-115

Verde se projeta nas coisas exteriores, com todo peso de sua rica vida interior, a fim de apreender a imagem fugaz das coisas, em perpétuo dinamismo. $\mathrm{O}$ poeta necessita se ver frequentemente nas coisas para atingir o claro equilíbrio do verso.” (MOISÉS, 1994, p 219; grifos meus).

Também Fernando Pessoa adotará o recurso do registro da memória, como pretendo comentar adiante. Sendo assim, apenas como elemento facilitador, divido este rápido estudo em duas partes, a relativa a Cesário Verde e a relativa a Fernando Pessoa.

Em "Num bairro moderno", à medida que vai descrevendo a paisagem do bairro, o eu lírico relaciona os seres humanos que vê aos legumes e vegetais que observa na feira. Isso traz-nos à memória os quadros de Giuseppe Arcimboldo ${ }^{3}$, artista quinhentista famoso pelas telas nas quais vegetais são transformados em figuras humanas. Nas estrofes VII a XII, Verde, à maneira do pintor renascentista, forma as imagens humanas nos legumes que vê: "E eu recompunha, por anatomia, / Um novo corpo orgânico, aos bocados. / Achava os tons e as formas. Descobria / Uma cabeça numa melancia, / E nuns repolhos seios injetados". Nas azeitonas, enxerga "as tranças de um cabelo que se ajeite"; nos nabos, ossos da cor do leite, nos cachos de uva, os rosários de olhos, e, entre as hortaliças, um melão que lhe lembra um ventre. Para completar essa longa descrição de um corpo humano em formação imagética:

E, como um feto, enfim, que se dilate,

Vi nos legumes carnes tentadoras, Sangue na ginja vívida, escarlate, Bons corações pulsando no tomate

E dedos hirtos, rubros, nas cenouras.

Se nos quadros o pintor imita a natureza física e visualmente, em Verde a visão é descrita com pormenores que, ao se juntarem, formam a imagem daquilo que o descritor presencia - agora num momento em que surgem na Europa os movimentos vanguardistas, entre eles aquele de que Verde se serve: o Impressionismo. É sob a luz e as cores que o eu

\footnotetext{
3 "Mas o pintor milanês era um maneirista, e, portanto, a intenção de suas obras era criar distorções da realidade, e não registrá-la em seus menores aspectos, como é o caso do nosso autor português [Cesário Verde]. Quando enxerga "colos, ombros, bocas, um semblante/ na posição de certos frutos", o poeta apenas associa formas, acentua as sensações de vitalidade, cria texturas, evoca sabores e cheiros, procura fazer com que possamos sentir, de fato, aquilo que nos mostra." (GOUVEIA, 2006). Carlos Felipe Moisés, em $O$ desconcerto do mundo..., ao comentar o poema de Cesário Verde, publica um dos famosos quadros do maneirista Arcimboldo para mostrar a similaridade entre poema e pintura (cf. p. 212).
} 


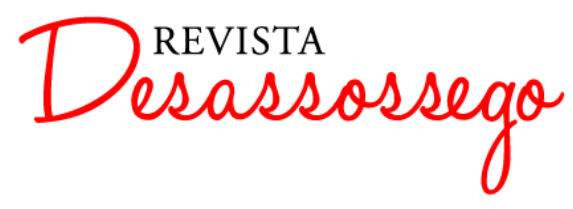

DESASSOSSEGO 15 | JUN/2016 | ISSN 2175-3180

DOI: http://dx.doi.org/10.11606/issn.2175-3180.v8i15p102-115

lírico vai formando as imagens e registrando o momento quando as cores se relevam em função de uma luz, que, pelo que diz em seus versos, acontece às dez horas da manhã:

Dez horas da manhã; os transparentes

Matizam uma casa apalaçada;

Pelos jardins estancam-se as nascentes,

E fere a vista, com brancuras quentes,

A larga rua macadamizada.

Ao apresentar diversos conceitos sobre a imagem, Maurício Silva Gino, escreve que Jacques Aumont "reconhece a existência de uma grande diversidade de significados para a palavra imagem, mas limita-se, em seu livro, somente àquelas que possuem uma forma visível, ou às que chama de imagens visuais. (...) Para ele, imagem é, portanto, uma forma de registro gráfico, algo com existência física e produzido pelo homem com uma certa intencionalidade" (GINO, 2010, pp. 72-73). Assim se expressa Aumont, conforme registra Gino: "a imagem tem inúmeras atualizações potenciais, algumas se dirigem aos sentidos, outras unicamente ao intelecto, como quando se fala do poder que certas palavras têm de produzir imagens" (Idem, p. 72). Utilizando-se dessas palavras que potencialmente produzem imagens, nas descrições de Cesário, o que se observa é a prática do conceito horaciano ut pictura poesis. Plutarco já havia mencionado o fato de as duas artes terem afinidades, atribuindo ao poeta Simônides de Céos o dito "a pintura é poesia calada e a poesia, pintura que fala" (De Gloria Atheniensium, 346 F). Plutarco esclarece que a pintura e a poesia são imitações da natureza, "princípio este que se revelaria fulcral nas reformulações sofridas pela analogia entre ambas as artes ao longo da Antiguidade clássica" (CEIA, s.d., s.p.). Esse fato foi muitas vezes contestado, outras, levado em máxima consideração. Durante o Realismo e o Parnasianismo, por exemplo, a máxima foi adotada e ela se revela no poema "Num bairro moderno" - à medida que o poeta descreve, monta paisagens pictóricas que formam imagens do cenário por que deambula o eu lirico. Neste fazer poesia por quadros, muito óbvio, é a seleção das palavras que reforça sua intenção de registro (memória?) do instante, para que fique guardado na mente do leitor (assim como ficou na mente do observador).

Em paralelo ao impressionismo pictórico que Cesário emprega em seus versos, avultam neles as descrições subjetivas, em que as sensações causadas no eu lírico provêm do exterior, alterando seu estado de espírito: “Como é saudável ter o seu conchego, / E a 
sua vida fácil!"; "E recebi, naquela despedida, / As forças, a alegria, a plenitude, / Que brotam dum excesso de virtude / Ou duma digestão desconhecida", ou ainda as sensações expressas nos diminutivos quando se refere à regateira: "pequenina, bracinhos, pequerrucho, enfezadita”. Como relatam António José Saraiva e Óscar Lopes, "tudo ganha volume: o sonho não diminui a vida: alimenta-se dela e a ela volta, a tonificar-se" (SARAIVA \& LOPES, s.d., p. 967), o que, sem dúvida, reforça a tese de que a subjetividade, mesmo que num poema tão descritivo e ao gosto dos realistas, é o leitmotiv do poema de Cesário. Para Carlos Felipe Moisés,

a subjetividade em Cesário abdica do sentimentalismo e do derramamento, torna-se natural, relativamente disciplinada, guiada pelo senso de observação do real. Tal atitude não exclui, ao contrário estimula a emotividade e os dons da fantasia, e se compraz sobretudo na exacerbação dos sentidos, muitas vezes através de ousados jogos sinestésicos. Como não podia deixar de ser, avulta no processo a importância da visualidade (MOISÉS, 2001, p. 212).

O subjetivo no poema "Num bairro moderno", em que a realidade se revela pelo fato de a impressão do eu lírico se sobrepor àquelas imagens destacadas pelo instante de luminosidade que atinge o objeto focalizado, revela uma das características do Impressionismo. No poema, esse impressionismo está exatamente no flagrante de um ambiente específico; o poeta procura expressar as impressões à medida que vão se revelando por instantes. É um texto realista, certamente, pelo concreto e pelo descritivo que retrata; mas nele se encontra um olhar subjetivo, que vai selecionando e valorizando os objetos: mais do que a representação do real, importa a impressão do real. A realidade apresenta-se mediada pelo olhar do poeta, que recria, a partir do concreto, outra realidade através da imaginação, reinventando outra contextualização ${ }^{4}$.

Além do impressionismo e da subjetividade, a poesia de Cesário é, sem dúvida, também plástica, uma vez que deixa ressaltar a visualidade, cuja relação com o impressionismo é premissa básica; o exterior é mostrado principalmente pela descrição revelada pela linguagem poética - fazendo relação com a fotografia, com o cinema (observem-se os flashes), mas principalmente com a pintura - o que faz com que Jorge

4 "O poeta identifica-se com o objeto pela sua sensibilidade (do poeta) e seu mundo interior. Há fusão da realidade objetiva com a subjetiva; só pelo esforço das faculdades totais é que o poeta consegue enxergar um plano. O subjetivo no entanto dá a nota; o exterior é prolongamento da mente do poeta. Com isso a invocação, a mentalização do objeto é que é a realidade, o "realismo" (MOISÉS, 1994, pp. 218-219). 
Luiz Antonio enquadre a poesia de Verde no Realismo Impressionista. De acordo com o estudioso, haveria razões históricas para isto, tendo em vista que todos os biógrafos do poeta português assinalavam que, em 1881, o poeta passara a conviver com os artistas e literatos que se reuniam no Leão de Ouro, na Rua do Príncipe, sob a designação de "Grupo do Leão”. (ANTONIO, 2002, p. 67). A comparação da composição poética de Cesário ao pictórico impressionista assume em seus versos um caráter marcante: cores claras e transparências luminosas surgem na construção do quadro matutino. O poeta conduz o olhar do leitor ao afunilar a imagem e concentrar a sensação: parte do externo e abrangente (a rua), para o mais específico e restrito, (as casas, na verdade, os lares, e finalmente o indivíduo).

Como recurso poético, ligado ao Realismo, Verde "introduziu no verso o processo queirosiano de suprir pelo adjectivo ou pelo advérbio uma relação lógica extensa, de imediatizar, pela surpresa da relação verbal, uma sugestão que morreria se fraseologicamente se desdobrasse”, como relatam António José Saraiva e Óscar Lopes (s.d., p. 967). São exemplos os versos de "Num bairro moderno": “Aonde agora quase sempre chego / Com as tonturas duma apoplexia"; "E rota, pequenina, azafamada, / Notei de costas uma rapariga"; "Se ela se curva, esguelhada, feia, / E pendurando os seus bracinhos brancos". No entanto, registre-se que esse realismo, ao menos naqueles poemas em que a descrição prevalece, não pretende ser um manifesto da estética, mas sim de uma subjetividade que somente pode se expressar através das descrições sinestésicas ("E fere a vista, com brancuras quentes"; "Boiam aromas, fumos de cozinha"; "Chegam do gigo emanações sadias,") além dos recursos ornamentais, tais como a hipálage ("Rez-dechaussée repousam sossegados"; "Reluzem, num almoço, as porcelanas."; "E às portas, uma ou outra campainha / Toca, frenética,"); a metáfora (“São tranças dum cabelo que se ajeite; / E os nabos - ossos nus, da cor do leite, / E os cachos de uvas - os rosários de olhos.") e a comparação ("E, como as grossas pernas dum gigante, / Sem tronco, mas atléticas, inteiras, / Carregam sobre a pobre caminhante, / Sobre a verdura rústica, abundante, / Duas frugais abóboras carneiras."). Outro recurso de que se vale Cesário é a ironia sutil. Nas primeiras estrofes, o eu lírico critica, por exemplo, os que moram na "casa apalaçada" e que só conhecem a Natureza através de "nascentes estancadas", de "quartos estucados", de "ramas em papéis pintados". Ainda, na estrofe 6, um criado, cheio de desprezo, atira "um cobre lívido" sobre a "rapariga pequenina e azafamada". É a partir da 


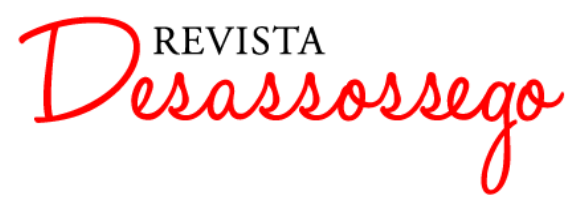

DESASSOSSEGO 15 ～JUN/2016 | ISSN 2175-3180

DOI: http://dx.doi.org/10.11606/issn.2175-3180.v8i15p102-115

estrofe 7, com o advérbio "subitamente", que começa o processo pictórico e descritivo de transformação.

Em A literatura portuguesa através dos textos, Massaud Moisés diz que a obra de Verde contém um "lirismo dum repórter, mas dum repórter atraído pela cidade, sensível a todas as suas pulsações, inclusive as nauseantes, disformes ou repugnantes. Ou, por outra, lirismo 'realista' porém não fotográfico ${ }^{5}$ nem frio: o poeta emociona-se, e muito, e é sua emoção perante o real cotidiano que procura transmitir ao leitor" (MOISÉS, 1997, pp. 303-304). Massaud, aqui, reforça a impressão de que prevalece nos poemas essencialmente descritivos de Cesário a emoção, o que o desloca, de certa forma, do realismo "puro". No entanto, não se pode concordar quando Moisés diz lirismo "não fotográfico" ao se referir à falta de frieza do poeta; pelo contrário, é com as palavras que ele vai descrevendo a paisagem urbana como uma fotografia do instante e dos objetos exteriores que o emocionam - cria verbalmente as imagens. O próprio poeta corrobora o que aqui se diz: "pinto quadros por letras, por sinais". Criando fotogramas, o poeta dá as nuanças da paisagem, bem como das ações de seus habitantes - aqui, em "Num bairro moderno", ao perambular e presenciar os trabalhadores de uma feira.

A Lisboa em que Cesário Verde viveu, assim como toda a Europa, passava por transformações advindas do nascimento da grande indústria, o desenvolvimento dos transportes e das comunicações, o lançamento das vias férreas, a expansão das linhas rodoviárias, enfim, uma revolução tecnológica e social. Testemunhou ainda outras melhorias modernas, tais como o telégrafo, a iluminação a gás nas ruas, os transportes coletivos, os primeiros candeeiros elétricos. Era ainda uma Lisboa desconfortável, insalubre, doentia, devido à insuficiência de água fornecida em domicílio, à insuficiência de esgotos, à acumulação de despejos nas ruas, aos estrumes dos currais etc. Ao passear por ela, o poeta começa a reparar nas ruas da sua cidade, observando as atmosferas mórbidas e sensuais, absorvendo os cheiros, os ruídos, examinando o pavimento das ruas e os perfis de seus transeuntes. Pelas janelas, viu-lhes os interiores. Também inventariou os comércios e os cafés e seus frequentadores. Como ligação entre essa evolução e seu poema, não é por acaso que escolhe o título de "Num bairro moderno", o adjetivo justamente qualificando os dias por que passa a principal cidade de Portugal.

\footnotetext{
${ }^{5}$ Também Carlos Felipe Moisés refere-se a esse lirismo não fotográfico ( $c f$. MOISÉS, 2001, p. 212).
} 
Seguindo para o final do século XIX, Cesário Verde despontará em Portugal pelo fato de - como dizem as antologias - ter sido o primeiro a fazer lirismo de assuntos nada poéticos (SERRÃO, 1986), mais especificamente quanto à nova sociedade que crescia nos centros urbanos, cercada de novos personagens frutos da industrialização. É claro que, nesta fase realista da Literatura, outros poetas se valeram desses fatos. Há muito disso em Cesário Verde, mas tome-se apenas um excerto de "Noite fechada", em que o poeta descreve de forma lírica, em metros irregulares decassílabos e hendecassílabos, a Lisboa do século XIX.

Toca-se às grades, nas cadeias. Som

Que mortifica e deixa umas loucuras mansas!

A aljube, em que hoje estão velhinhas e crianças,

Bem raramente encerra uma mulher de "Dom"!

E eu desconfio, até, de um aneurisma

Tão mórbido me sinto, ao acender das luzes;

À vista das prisões, da velha Sé, das Cruzes,

Chora-me o coração que se enche e que se abisma.

(...)

Esse pessimismo em relação à cidade leva frequentemente Cesário a exaltar as qualidades da vida campesina, o que faz com certa persistência, como que revivendo os poemas bucólicos de um Sá de Miranda ou mesmo de Gil Vicente. Sobre esse bucolismo, o crítico português Carlos Cunha comenta e acredita ser extensão do tema à maneira de Gil Vicente:

Para o bucolismo clássico, os objectos, despidos da sua função decorativa, vivencializam-se e agem como elementos duma simbologia implícita na necessidade de convívio do poeta com a natureza. É o que acontece nas cantigas de amigo. É o que acontece em "Diana" de Montemor. É o que acontece nas éclogas de Bernardim, Falcão e Rodrigues Lobo (...). Ora o que a meu ver distingue o bucolismo de Cesário Verde de todos que o precederam é precisamente o novo conceito de realidade que o sentido do útil e do vital lhe imprime

$$
\begin{aligned}
& \text { Ah! O campo não é um passatempo } \\
& \text { Com bucolismos, rouxinóis, luar. }
\end{aligned}
$$

Novo, é certo, mas cuja novidade nada particulariza de insólito, pois se articula na fértil tradição dum Gil Vicente que, na sua "Tragicomédia Pastoril da Serra da Estrela", celebra já, com genial antecipação, as gordas bezerras, ovelhas e cordeirinhas (...). E assim, superando o provincianismo que limita o panorama da nossa literatura, o autor do Livro se situa na linha mais alta do bucolismo moderno (CUNHA, 1955, pp. 23-25). 
Carlos Felipe Moises, em $O$ desconcerto do mundo..., comenta que:

graças à atuação do poeta pelo banal e o vulgar, pelos aspectos grotescos da grande urbe, opressiva e anônima, a poesia de língua portuguesa ingressa de corpo inteiro na era industrial. $\mathrm{E}$ com isso começa a ruir o antigo edifício das Verdades e Belezas eternas. O espaço poético delineado por ele é governado pelo transitório e o efêmero, e daí brota uma imagem da existência como fragmentação e dispersão. Perplexa, a consciência do poeta vê-se impregnada da presença objetiva da realidade circundante, que ao mesmo tempo repele e fascina. É por demais evidente a modernidade dessa faceta de Cesário (MOISÉS, 2001, pp. 215-216).

É então que Cesário, pelas palavras, monta imagens de uma nova cidade, intentando registrar o que vê da paisagem. Coloca na escrita uma "memória seletiva, tão importante para nos permitir sobreviver como indivíduos, funciona também em nível social e permite a sobrevivência das comunidades", conforme aludi no início referindo-me a Umberto Eco.

Na biografia de Alberto Caeiro, seu criador, Fernando Pessoa, nos diz que o heterônimo foge de Lisboa para o campo ${ }^{6}$. Assim como Cesário, que exaltava o campo, após as experiências citadinas. Caeiro, por encontrar nele a liberdade que procura para suas reflexões, tem na memória a cidade como elemento negativo para a expressão da naturalidade, que só encontra no campo. O encontro de ideias a respeito da cidade é tão relevante em Caeiro que ele escreve sobre Cesário: “Ao entardecer, debruçado pela janela, / E sabendo de soslaio que há campos em frente, / Leio até me arderem os olhos / O livro de Cesário Verde. // Que pena que tenho dele! Ele era um camponês / Que andava preso em liberdade pela cidade". Note-se que o poeta se identifica com Verde e dele diz ter pena porque era um camponês "preso em liberdade", dando força à antítese que vem, de certa forma, mascarar à frente: a grande tristeza que Cesário tinha "ele nunca disse bem que tinha”, pois que o poeta da cidade ainda se deixava deslumbrar por ela, até que chegue o momento da decepção total mostrada em "Num bairro moderno". Note-se, também, que a antítese "preso em liberdade" mostra o que já sentiu Caeiro e que, de certa forma, condói-

6 “Alberto Caeiro, 'nascido' a 8 de maio de 1914 e mestre dos demais, é o poeta que foge para o campo, pois sendo poeta e nada mais, poeta por natureza, deve procurar viver simplesmente como as flores, os regatos, as fontes, os prados, etc., que são felizes apenas porque, faltando-lhes a capacidade de pensar, não sabem que o são: 'O essencial é saber ver, / Saber ver sem estar a pensar, / Saber ver quando se vê, / E nem pensar quando se vê, / Nem ver quando se pensa". (MOISÉS, 1994, p. 300). 


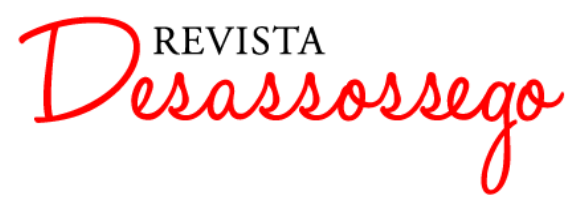

DESASSOSSEGO 15 | JUN/2016 | ISSN 2175-3180

DOI: http://dx.doi.org/10.11606/issn.2175-3180.v8i15p102-115

se com Verde - isso tudo corroborado por outro substantivo, "pena", que revela sua intimidade com o sentimento de seu inspirador. Ao longo de "Ao entardecer", Caeiro vai registrando de forma comparativa a deambulação de seu inspirador - ao olhar a concretude das coisas modernas, aliá-las às coisas naturais, próprias do campo. O poeta aqui registra, como que entrando no pensamento de Cesário, as marcas que o prendem a seu inspirador; depreende-se que ambos, ao registrarem a memória impregnada pela cidade, o fazem pela comparação e pelo pictórico.

Anteriormente, comentei sobre a plasticidade de Cesário Verde. Assim se manifesta Fernando Pessoa sobre a questão:

Segundo característico da objetividade poética é aquilo que podemos chamar a plasticidade; e entendemos por plasticidade a fixação do visto ou ouvido como exterior, não como sensação, mas como visão ou audição. Plástica, nesse sentido, foi toda a poesia grega e romana, plástica a poesia dos parnasianos, plástica (além de epigramática e mais) a de Victor Hugo, plástica, de novo modo, a de Cesário Verde. A perfeição da poesia plástica consiste em dar a impressão exata e nítida (sem ser exatamente epigramática) do exterior como exterior, o que não impede de, ao mesmo tempo, o dar como interior, como emocionado." (PESSOA, 1912, pp. 8/22).

É notória a convergência entre Fernando Pessoa - o crítico literário - e Cesário Verde - aqui, parece, Pessoa, assim como faz em relação a outros poetas, relaciona a plasticidade ao impressionismo, tanto é que a impressão do que é visto e ouvido exteriormente deve ser exato e nítido. Mas ainda aqui, além dessa referência e analogia do plástico à impressão no registro do real, Pessoa refere que esse registro deve ser também interior e de modo emocionado. Valoriza, então, a subjetividade, como acima relatei, acerca das impressões subjetivas de Cesário.

Outro ponto de convergência entre Verde e Pessoa pode-se relacionar à emoção, ao subjetivismo que ambos empregam em seus poemas. De Cesário, já tive oportunidade de registrar. De Pessoa, ajuda-me Massaud Moisés, quando afirma:

a emoção, sendo extremamente móvel e passageira, tende a desaparecer caso o poeta não a transmita. A angústia dele reside, portanto, em apreendê-la e transmiti-la: o poeta menor é essencialmente emocional, ou melhor, não utiliza a inteligência na captação de suas emoções, de que resulta transmitir-nos antes uma lembrança das emoções, que elas próprias. O grande poeta surpreende-as, analisa-as, fixa-as e enriquece-as por meio da inteligência; com isso são as próprias emoções que ele nos comunica, 
como se o poeta fosse apenas o veiculo de sua transmissão, e as emoções se mantivessem tais como se desenvolveram em sua sensibilidade... para conhecer a intimidade do objeto, fosse necessário desmanchá-lo, à semelhança das crianças e seus brinquedos. (MOISÉS, 1994, p. 302).

Em seu exílio no campo, em “O Guardador de rebanhos”, poema VII, Caeiro dá tamanha dimensão à sua aldeia que diz: dela "vejo quanto da terra se pode ver no Universo"; por isso sua aldeia é "tão grande como outra terra qualquer", querendo dizer que onde ele está tem a dimensão do universo. E esse universo é do tamanho dele mesmo, o eu lírico. A partir dessa constatação, desce à dimensão mais mundana e diz que "nas cidades a vida é mais pequena" que sua própria casa, de onde vê o mundo. É então que registra sua experiência pela comparação: a opressão citadina começa pelo ato de fechar a vista à chave, o que faz com que o horizonte seja escondido e o habitante dessas cidades procure no céu uma significação que não encontra aqui. Essas cidades tiram dos olhos aquilo que só eles podem nos dar: a capacidade de ver. Ora, a partir da constatação de que o eu lírico é do tamanho do que vê, ele só pode ver-se a si mesmo se os olhos atingirem o horizonte. É onde, no campo aberto, que todo o horizonte se mostra aos olhos para que, no caso de Caeiro, ele possa refletir sobre o mundo e si mesmo (GOUVEIA, 2006).

Em vários dos poemas que formam o extenso "Guardador de rebanhos", vale relembrar, são os verbos "ver" e "ouvir" os condutores do pensamento de Caeiro. E isso se centra nos olhos - "Penso com os olhos e com os ouvidos", pois "o que vemos das coisas são as coisas". Ao dizer isso, o eu lírico expressa aparentemente o mais puro naturalismo e simplicidade. A análise do verso - na verdade, dos versos em que "ver" e "ouvir" são determinantes - pretende abolir o pensamento (através das conjugações do verbo "pensar"), o que é mero artifício, já que o poeta não para de pensar. Esse artifício mostra-se claro nos versos "Pensar incomoda como andar à chuva / Quando o vento cresce e parece que chove mais" - aqui o poeta nada mais faz do que pensar, pois uma das características do pensar é justamente ter a consciência de que o ato nos incomoda. No entanto, a substancialidade deste pensar não está no modo, poder-se-ia dizer, "simples", mas sim, ampliado ao verbo relativamente conexo ao pensar: refletir ${ }^{7}$. Como afirma Massaud Moisés, o poeta parece valorizar "uma concepção ingênua e 'realista' das coisas",

\footnotetext{
7 "Fernando Pessoa parte sempre de verdades apenas aparentemente axiomáticas, e aparentemente porque, primeiro, resultam dum longo e acurado trabalho de reflexão analítica em torno daquilo que é motivo de seus poemas; e segundo, porque contêm sempre uma profunda dualidade dialética que lhes destrói facilmente a fina crosta de verdade dogmática" (MOISÉS, 1994, p. 298).
} 
mas "nem por isso deixa de ser altamente intelectualizada e pensada", pois seu propósito é pensar. (MOISÉS, 1997, pp. 403-404). À medida que pensa, o que faz Caeiro é ver e ouvir o que lhe apresenta o exterior e registra-o em versos. Ao fazer o registro, o poeta expõe o que reteve na lembrança, expõe os dados de sua experiência precedente, como diz o referido Umberto Eco. Mas Caeiro retém outra função da memória, que é "a de filtrá-los [os dados de sua experiência], de descartar alguns e conservar outros".

No "Guardador", as únicas referências à cidade vêm nos poemas III, VII e XXXII. O poema III, Caeiro o dedica a Cesário Verde (“Ao entardecer”), cujos versos viram-se acima. No XXXII, a cidade é citada apenas porque um homem desabafa a Caeiro sobre a justiça e a falta dela na cidade, principalmente em relação aos operários e aos que têm fome. Lágrimas vêm aos olhos do poeta camponês e o homem acredita que as lágrimas sejam devidas ao drama que relata; mas Caeiro confessa que mal o ouvia, pois, "que me importa a mim os homens / E o que sofrem ou supõem que sofrem”. No poema VII, a intenção, parece, é fazer um corte em relação a tudo que versou nos primeiros poemas e em relação ao que se estenderá quase que ad infinitum - é nele que sabemos sobre seu desencanto com a cidade opressora. A escolha desse poema por comparação ao de Cesário teve a intenção de mostrar a visão de cidade entre Cesário e Caeiro. Decepcionados com a cidade, é para o campo, então, que se voltam os poetas, como expressão de espíritos inconformados.

Para ajudar Caeiro em seu desprezo em relação à cidade, aparece Álvaro de Campos. Contrariamente ao que parece, pois Campos é vanguardista e cosmopolita, refletindo em seus poemas a exaltação da civilização moderna e dos valores do progresso, em uma de suas odes, o poeta também critica a cidade. Com um estilo torrencial, amplo, delirante e até violento, mostrando muitas das vezes a civilização industrial e mecânica, expressa o desencanto do cotidiano citadino, quando em versos cita seu Mestre, Cesário Verde:

Ah o crepúsculo, o cair da noite, o acender das luzes nas grandes [cidades

E a mão de mistério que abafa o bulício,

E o cansaço de tudo em nós que nos corrompe

Para uma sensação exacta e precisa e activa da Vida!

Cada rua é um canal de uma Veneza de tédios

$\mathrm{E}$ que misterioso o fundo unânime das ruas,

Das ruas ao cair da noite, ó Cesário Verde, ó Mestre, 


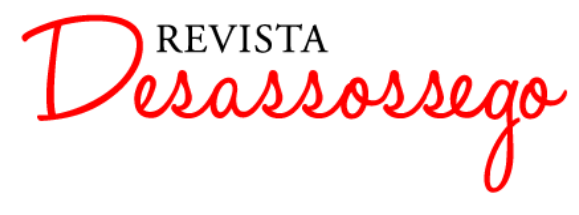

DESASSOSSEGO 15 | JUN/2016 | ISSN 2175-3180

DOI: http://dx.doi.org/10.11606/issn.2175-3180.v8i15p102-115

Ó do “Sentimento de um Ocidental!" (PESSOA, 1944, p. 160).

Esta confluência de citações a Cesário marca o registro da admiração de Pessoa por Verde. Pode-se dizer que, além de confluência, há mesmo influência de Cesário em Pessoa $^{8}$. Num termo tão trivial, a cidade, ambos os poetas - Pessoa principalmente em seus heterônimos - desenvolvem uma paixão que se mostra delusional, mas às vezes de deslumbramento. Não deixam de ser é intrigantes, se virmos que a cidade é o tema que permite a Verde pintar um quadro por palavras e que permite a Caeiro externar sua filosofia, a do homem campesino, mas não menos intelectual.

Como foi mostrado no início deste estudo, Umberto Eco disserta sobre a memória e suas características, em uma obra que homenageia e faz exaltação do livro ( $A$ memória vegetal). Creio que tanto Cesário Verde quanto Fernando Pessoa, na pele de Alberto Caeiro, valeram-se do que suas férteis memórias registraram e as colocaram em poemas, densos, ricos e extremamente deleitosos, pela qualidade estética e pela inovação.

\section{BIBLIOGRAFIA}

ANTONIO, Jorge Luiz. Cores, Forma, Luq, Movimento: A Poesia de Cesário Verde. São Paulo: Musa Editora/ FAPESP, 2002.

CEIA, Carlos. E-Dicionário de termos literários. Disponível em:

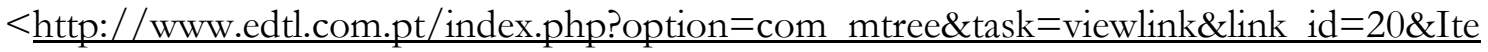
$\leq$ mid $=2>$. Acesso em 3 maio, 2015.

CUNHA, Carlos. Cesário, poeta moderno. Braga: Cruz, 1955.

ECO, Umberto. A memória vegetal e outros escritos sobre bibliofilia. Trad. Joana Angélica d'Ávila. Rio e Janeiro-São Paulo: Record, 2010.

GINO, Maurício Silva. Hibridismo gráfico e mesclagem conceitual: uma relação entre o pensamento de Sartre e as teorias da cognição. IN: Leitura e escrita em movimento, RIBEIRO, Ana Elisa ET alii. São Paulo: Peirópolis, 2010.

${ }^{8}$ Como relata Massaud Moisés, a “'comédia humana' poética duma cidade sombria e triste (a Lisboa dos fins do século XIX), 'O sentimento de um ocidental' denuncia em Cesário Verde um lírico insatisfeito, visionário de espaços e belezas, que viriam a ser conhecidos de um Fernando Pessoa e de um Mário de Sá-Carneiro, que, desse modo, podem ser considerados realmente discípulos ou continuadores". (MOISÉS, 1997, p. 304). 
GOUVEIA, Maiara. A plasticidade na poesia de Cesário Verde. Agulha, Revista de Cultura. Fortaleza-São Paulo, n. 52, julho-agosto, 2006. Disponível em: http://www.jornaldepoesia.jor.br/ag52verde.htm. Acesso em 3 de maio, 2015.

LE GOFF, Jacques. História e memória. Trad. Bernardo Leitão. Campinas: Unicamp, 1996.

MOISÉS, Carlos Felipe. O desconcerto do mundo: do Renascimento ao Surrealismo. São Paulo: Escrituras, 2001 (Coleção Ensaios Transversais).

MOISÉS, Massaud. A literatura portuguesa. São Paulo, Cultrix, 1994. , A literatura portuguesa através dos textos. São Paulo, Cultrix, 1997.

PESSOA, Fernando. Dois excertos de odes (Fins de duas odes, naturalmente). Poesias de Álvaro de Campos. Lisboa, Ática, 1944 (imp. 1993) -160. (30-6-1914). Disponível em http://arquivopessoa.net/textos/129. Acesso em 3 de maio, 2015 A nova poesia portuguesa no seu as/pecto psicológico. Disponível em: http://arquivopessoa.net/typographia/textos/arquivopessoa-3101.pdf. Acesso em 3 de maio, 2015.

SARAIVA, António José \& LOPES, Óscar. História da literatura portuguesa. Porto: s.d.

SERRÃO, Joel. O essencial sobre Cesário Verde. Lousã: IN-CM, 1986.

VERDE, Cesário. Poesias Completas de Cesário Verde. Rio de Janeiro: Ediouro, 1987. Texto proveniente de: A Biblioteca Virtual do Estudante Brasileiro http://www.bibvirt.futuro.usp.br. 